T. Skrivarhaug $\cdot$ H.-J. Bangstad $\cdot$ L. C. Stene $\cdot$

L. Sandvik · K. F. Hanssen - G. Joner

\title{
Long-term mortality in a nationwide cohort of childhood-onset type 1 diabetic patients in Norway
}

Received: 7 July 2005 / Accepted: 4 October 2005 / Published online: 20 December 2005

(C) Springer-Verlag 2005

\begin{abstract}
Aims/hypothesis: We examined long-term total and cause-specific mortality in a nationwide, populationbased Norwegian cohort of patients with childhood-onset type 1 diabetes. Materials and methods: All Norwegian type 1 diabetic patients who were diagnosed between 1973 and 1982 and were under 15 years of age at diagnosis were included $(n=1,906)$. Mortality was recorded from diabetes onset until 31 December 2002 and represented 46,147 person-years. The greatest age attained among deceased subjects was 40 years and the maximum diabetes duration was 30 years. Cause of death was ascertained by reviews
\end{abstract}

T. Skrivarhaug et al.: Mortality of type 1 diabetes in Norway

Electronic Supplementary Materials Supplementary material is available in the online version of this article at http://dx.doi. org/10.1007/s00125-005-0082-6.

T. Skrivarhaug $\cdot$ H.-J. Bangstad $\cdot$ G. Joner

Department of Pediatrics,

Ullevål University Hospital,

N-0407, Oslo, Norway

L. C. Stene

Division of Epidemiology,

Norwegian Institute of Public Health,

Oslo, Norway

L. Sandvik

Centre for Clinical Research,

Ullevål University Hospital,

Oslo, Norway

K. F. Hanssen

Department of Endocrinology,

Aker University Hospital,

Oslo, Norway

T. Skrivarhaug $(\bowtie) \cdot$ H.-J. Bangstad · L. C. Stene ·

K. F. Hanssen - G. Joner

Diabetes Research Centre,

Aker and Ullevål University Hospitals,

Oslo, Norway

e-mail: torild.skrivarhaug@medisin.uio.no

Tel.: +47-23015648

Fax: $+47-23015790$ of death certificates, autopsy protocols and medical records. The standardised mortality ratio (SMR) was based on national background statistics. Results: During follow-up 103 individuals died. The mortality rate was $2.2 / 1000$ person-years. The overall SMR was 4.0 (95\% CI 3.2-4.8) and was similar for males and females. For ischaemic heart disease the SMR was $20.2(7.3-39.8)$ for men and 20.6 (1.8-54.1) for women. Acute metabolic complications of diabetes were the most common cause of death under 30 years of age (32\%). Cardiovascular disease was responsible for the largest proportion of deaths from the age of 30 years onwards $(30 \%)$. Violent death accounted for $28 \%$ of the deaths in the total cohort (35\% among men and $11 \%$ among women). Conclusions/interpretation: Childhood-onset type 1 diabetes still carries an increased mortality risk when compared with the general population, particularly for cardiovascular disease. To reduce these deaths, attention should be directed to the prevention of acute metabolic complications, the identification of psychiatric vulnerability and the early detection and treatment of cardiovascular disease and associated risk factors.

Keywords Causes of death · Cohort study . Epidemiology $\cdot$ Standardised mortality ratio . Type 1 diabetes

Abbreviations CAD: coronary artery disease CVD: cardiovascular disease $\cdot$ DKA: diabetic ketoacidosis - ICD: International Classification of Diseases - IHD: ischaemic heart disease - RR: risk ratio . SMR: standardised mortality ratio

\section{Introduction}

Before the introduction of insulin therapy in 1922, few children with type 1 diabetes survived more than 1 or 2 years after the onset of symptoms [1]. After insulin became available for clinical use, a marked decrease in mortality was observed. In spite of this reduction in mortality, type 1 diabetes still has a two- to ten-fold excess 
risk of death in developed countries [2, 3]. Diabetes mellitus is known to be under-reported on death certificates as an underlying or contributing cause of death [4-6]. Cohort studies are the best way to assess the mortality risk among diabetic patients. However, long-term follow-up studies of mortality in subjects with childhood-onset type 1 diabetes are relatively rare [2, 5, 7-11]. Although few studies have been large enough to provide precise estimates of cause-specific mortality rates, there seems to be considerable variation in cause-specific mortality among patients with childhood-onset type 1 diabetes in different countries [7, 11-15]. In the present study, we report total and cause-specific mortality rates during the long-term follow-up of a nationwide cohort of patients with childhood-onset type 1 diabetes in Norway.

\section{Subjects and methods}

Subjects and study protocol

All new-onset cases of type 1 diabetes occurring in Norwegian children below 15 years of age during the period from 1 January 1973 to 31 December 1982 were registered retrospectively between 1985 and 1986 and included in the Norwegian Childhood Diabetes Registry [16]. The data were collected by contacting all the paediatric and medical hospital departments in Norway for information on all new patients aged $0-14$ years with type 1 diabetes during the study period. Persons were excluded if they developed diabetes from a secondary cause. The registry identified 1,912 new individuals with type 1 diabetes. Four were omitted from subsequent mortality analyses because of uncertainties regarding the date of diagnosis. Two subjects were excluded because of diagnostic misclassification, leaving a cohort of 1,906 individuals (1,034 males and 872 females). All persons with diabetes mellitus who received a basic allowance were registered by the National Insurance Institution and this registry was used as a secondary source for ascertainment of cases. The estimated case ascertainment level was greater than $98 \%$ [16].

Table 1 presents the demographic characteristics of the 1,906 subjects. The survival or emigration status and date of death or emigration of these 1,906 patients were determined as of 31 December 2002 by matching the unique personal identification number assigned to each resident of Norway to the Norwegian Population Registry and to the Cause of Death registry. All deaths were included, including deaths close to diabetes onset.

Cause of death was registered and classified in two ways for different purposes. (1) Information on the cause of death was obtained from death certificates and from the International Classification of Diseases (ICD) codes [1719] for the underlying cause of death in the Cause of Death registry. These data were used for comparing mortality rates with those of the background population. (2) Causes of death were ascertained by a clinical review
Table 1 Characteristics of childhood-onset $(<15$ years) type 1 diabetic patients in Norway, 1973-1982

\begin{tabular}{lcc}
\hline Characteristic & Number & Percentage (\%) \\
\hline Sex & & \\
Male & 1,034 & 54.2 \\
Female & 872 & 45.8 \\
Year of birth & & \\
1958-1962 & 178 & 9.3 \\
$1963-1967$ & 614 & 32.2 \\
$1968-1972$ & 731 & 38.4 \\
$1973-1977$ & 320 & 16.8 \\
1978-1981 & 63 & 3.3 \\
Year of diabetes onset & & \\
1973-1977 & 881 & 46.2 \\
1978-1982 & 1,025 & 53.8 \\
Age at onset (years) & & \\
$<5$ & 341 & 17.9 \\
5-9 & 695 & 36.5 \\
10-14 & 870 & 45.6 \\
Status at 31 December 2002 & \\
Alive & 1,778 & 93.3 \\
Dead & 103 & 5.4 \\
Emigrated & 25 & 1.3 \\
\hline
\end{tabular}

committee using all available sources of information, as described below.

Causes of death based on death certificates and the ICD codes from the cause of death registry

Information was obtained from death certificates and the ICD codes for the primary cause of death as listed on the death certificate registered by Statistics Norway, using only the ICD code for the underlying cause of death. This information is available on the whole population of Norway, including all deaths in the diabetes cohort. During the period of this study, the ICD codes in use were those given in Revision 8, 9 or 10. All codes were translated into the ICD 10 codes [17-19]. Because deaths coded to the underlying cause 'diabetes' might reflect a range of different short-term metabolic events or long-term degenerative complications, the full statements relating to cause of death were examined and all cardiovascular and renal deaths were recorded to the relevant categories for those diseases [20]. Otherwise the cause of death was taken as the underlying cause.

Causes of death assessed by the clinical review committee

Causes of death in the diabetes cohort were ascertained by a clinical review committee of three diabetologists (T. Skrivarhaug, H.-J. Bangstad, G. Joner) using all available sources of information, including hospital records, outpa- 


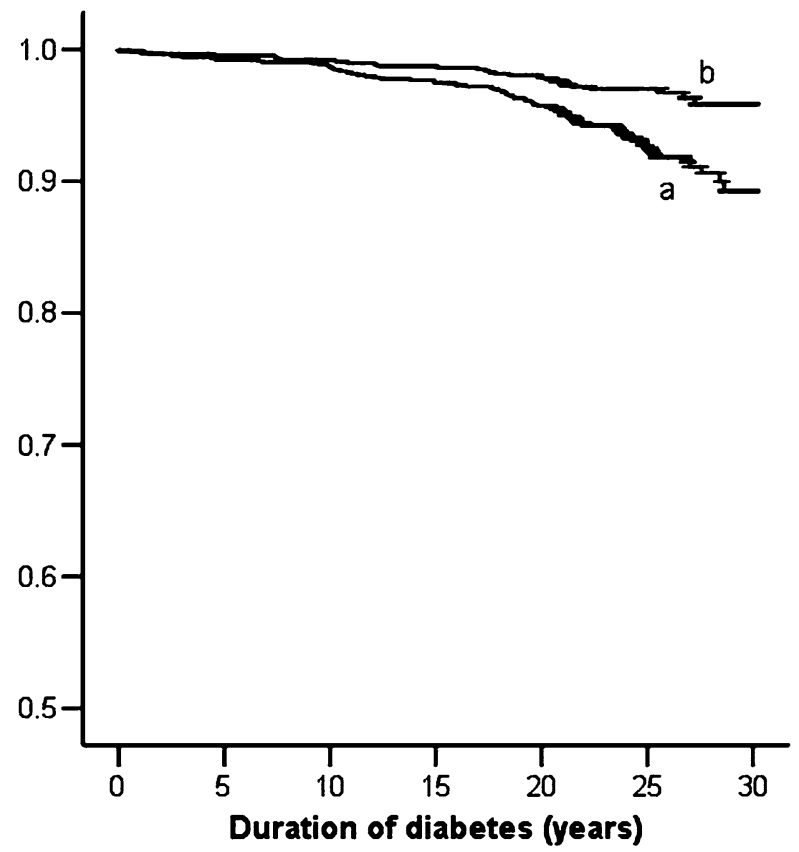

Fig. 1 Life-table analyses by sex, in individuals with childhoodonset type 1 diabetes who were diagnosed in Norway between 1973 and 1982. a male; b female

tient records, police reports, death certificates, post-mortem reports and necropsy reports. We obtained 20 out of 20 existing autopsy reports, 30 out of 33 coroner reports, 35 out of 35 post mortem reports, 91 hospital records and 31 police reports. For three patients, we only had access to the death certificate. The causes of death were grouped as follows:

1. Cardiovascular death (ICD-10: I20-I25, I44-I49, I60I69). This included cardiac and cerebrovascular death, and was subdivided as follows: (1) cardiac death (ICD10: I20-I25, I44-I49): acute myocardial infarction, fatal arrhythmia; (2) cerebrovascular death (ICD-10: I60-I69): ischaemic cerebral events and intracranial haemorrhagic events.

2. Renal death (ICD-10: N 18.8, N 19): death due to uraemia of any cause.

3. Acute metabolic complications of diabetes (ICD-10: E 10.0, E 10.1, E 14.0, E 14.1): hypoglycaemia, diabetic ketoacidosis (DKA).

4. Death caused by infection (ICD-10: A 41.9, B 95.4, J 18.0, J 18.8): any septicaemia or fatal infection.

5. Neoplasm (ICD-10: C 18.9, C 32.9): any fatal malignant disease.

6. Violent death (ICD-10:V01-Y89): fatal accidents, suicide, intoxication.

7. Sudden and unexpected death (R 96.0, R98, R99): no potentially fatal or critical event or disease present at least $24 \mathrm{~h}$ before death. Includes dead-in-bed (patient found dead in an undisturbed bed; observed to be in good health condition the day before; autopsy not informative).

To distinguish coronary artery disease (CAD) as the cause of death in patients with renal disease, CAD had to be proved either by autopsy or by clinical examination in an intensive care unit. Death in patients with end-stage renal
Table 2 Standardised mortality ratio (SMR) in a cohort of 1,034 men and 872 women with childhood-onset type 1 diabetes diagnosed between 1973 and 1982

${ }^{a}$ Norwegian mortality statistics [24]

\begin{tabular}{llccccc}
\hline Men & General population & \multicolumn{2}{l}{ Type 1 diabetes cohort } & & \\
\hline $\begin{array}{l}\text { Age group } \\
\text { (years) }\end{array}$ & $\begin{array}{l}\text { Mortality rate } \\
\text { (per 1,000 } \\
\text { person-years) }\end{array}$ & $\begin{array}{l}\text { Observed } \\
\text { number } \\
\text { of deaths }\end{array}$ & $\begin{array}{l}\text { Person-years } \\
\text { Expected } \\
\text { number } \\
\text { of deaths }\end{array}$ & SMR & $95 \%$ CI \\
\hline Men & & & & & \\
$0-4$ & 1.4880 & 1 & 341 & 0.5074 & 2.0 & $0.0-7.7$ \\
$5-9$ & 0.1511 & 1 & 1,780 & 0.2690 & 3.7 & $0.0-14.6$ \\
$10-14$ & 0.2218 & 4 & 3,911 & 0.8675 & 4.6 & $1.2-10.2$ \\
$15-19$ & 0.7166 & 12 & 5,102 & 3.6561 & 3.3 & $1.7-5.4$ \\
$20-24$ & 0.8752 & 10 & 4,990 & 4.3672 & 2.3 & $1.1-3.9$ \\
$25-29$ & 0.9381 & 19 & 4,474 & 4.1971 & 4.5 & $2.7-6.8$ \\
$30-34$ & 1.1388 & 22 & 3,047 & 3.4699 & 6.3 & $4.0-9.3$ \\
$35-39$ & 1.4270 & 6 & 1,262 & 1.8009 & 3.3 & $1.2-6.5$ \\
Total & 0.8570 & 75 & 24,907 & 19.1351 & 3.9 & $3.1-4.9$ \\
Women & & & & & & \\
$0-4$ & 1.2640 & 0 & 327 & 0.4133 & 0.0 & - \\
$5-9$ & 0.1550 & 0 & 1,523 & 0.2361 & 0.0 & - \\
$10-14$ & 0.1289 & 2 & 3,408 & 0.4393 & 4.6 & $0.4-13.0$ \\
$15-19$ & 0.2802 & 7 & 4,328 & 1.2127 & 5.8 & $2.3-10.8$ \\
$20-24$ & 0.2927 & 4 & 4,248 & 1.2434 & 3.2 & $0.8-7.1$ \\
$25-29$ & 0.3477 & 6 & 3,772 & 1.3115 & 4.6 & $1.7-9.0$ \\
$30-34$ & 0.5285 & 28 & 1,048 & 0.7426 & 2.7 & $0.3-7.7$ \\
$35-39$ & 0.7086 & 21,240 & 6.9656 & 4.0 & $2.7-5.6$ \\
Total & 0.4598 & & & & & \\
\hline
\end{tabular}


disease, where CAD could not be proved, was classified as renal disease.

The study was approved by the Regional Ethics Committee, the National Data Inspectorate and the Directorate for Health and Social Affairs. All subjects and/or their parents gave written informed consent to be included in the registry.

\section{Statistical analyses}

Statistical analysis was done using SPSS version 12 (SPSS, Chicago, IL, USA). The follow-up period for each patient was calculated from the date of the first insulin injection to the date of death, emigration, or to 31 December 2002, whichever occurred first. Excess mortality compared with the background population was assessed in terms of the standardised mortality rate (SMR). The SMR was calculated as the ratio of the observed to the expected number of deaths [21-23] using mortality rates in the general population for each sex, 5-year calendar period and age group, provided by Statistics Norway [24]. Cox regression analysis was used to study the effects of covariates (age at diagnosis, sex) on mortality.

\section{Results}

\section{Total mortality}

During follow-up, 25 individuals emigrated and 103 individuals $(5.4 \%)$ died: 75 out of 1,034 males $(7.3 \%)$ and 28 out of 872 females (3.2\%). During the first week after diagnosis, two deaths were reported (an 11-year-old girl in 1974 and a 13-year-old boy in 1975). Both died in hospital during the first $48 \mathrm{~h}$ after diagnosis because of DKA with cerebral oedema. The mean age of deceased subjects at death was 26.1 years (SD 7.8, range 0.8-40.2). The youngest person who died was diagnosed with type 1 diabetes at the age of 2 months and was treated with insulin. At 9 months of age he was found dead in his home with no previous symptoms of illness. The mean duration of follow-up was 24.2 years (SD 3.9, range 2 days to 30.0 years), the highest attained age among deceased subjects was 40 years and the total number of person-years accumulated during follow-up was 46,147. The overall mortality rate in the diabetes cohort was 2.2 per 1,000 person-years. The estimated cumulative survival according to diabetes duration was $98.9 \%$ at 10 years, $98.0 \%$ at 15 years, $96.7 \%$ at 20 years and $94.6 \%$ at 25 years. The mortality rate was 2.3 times higher in males than in females (3.0/1,000 vs $1.3 / 1,000$; risk ratio [RR] $2.31,95 \%$ CI 1.49 3.56). The difference in total mortality between the sexes is illustrated in the Kaplan-Meier plot in Fig. 1. Individuals with diabetes onset at age 10-14 years had a significantly higher mortality rate than those with onset below 10 years of age $(2.85 / 1,000$ vs $1.73 / 1,000$; RR $1.70,95 \%$ CI $1.15-$ 2.51). To look for any temporal trend in mortality, the cases diagnosed between 1978 and 1982 were compared over 20 years of disease duration with those diagnosed between
1973 and 1977. No significant difference in cumulative survival was found ( 0.963 vs $0.972, p=0.52$ ).

The SMR in the diabetic cohort was $4.0(95 \%$ CI $3.2-$ 4.8). There was no significant difference in SMR between males and females (Table 2).

\section{Cause-specific mortality}

Thirty-five of the deceased persons died in hospital, 40 died at home and 28 died elsewhere. An autopsy was performed in 12, 25 and 16 cases, respectively.

Table 3 Cause-specific deaths by age and sex in a cohort of 1,034 men and 872 women with childhood-onset type 1 diabetes diagnosed between 1973 and 1982, assessed by the clinical review committee

\begin{tabular}{|c|c|c|c|c|c|}
\hline \multirow[t]{2}{*}{ Cause of death } & \multicolumn{5}{|c|}{ Age at death (years) } \\
\hline & & $\begin{array}{l}0-19 \\
n(\%)\end{array}$ & $\begin{array}{l}20-29 \\
n(\%)\end{array}$ & $\begin{array}{l}30-40 \\
n(\%)\end{array}$ & $\begin{array}{l}\text { Total cohort } \\
n(\%)\end{array}$ \\
\hline \multirow{2}{*}{$\begin{array}{l}\text { Total cardiovascular } \\
\text { disease }\end{array}$} & M & $1(6)$ & $3(10)$ & $6(22)$ & $10(13)$ \\
\hline & $\mathrm{F}$ & 0 & 0 & $5(56)$ & $5(18)$ \\
\hline \multirow[t]{2}{*}{ Cerebrovascular death } & M & 0 & 1 & 3 & 4 \\
\hline & $\mathrm{F}$ & 0 & 0 & 1 & 1 \\
\hline \multirow{2}{*}{$\begin{array}{l}\text { Ischaemic heart } \\
\text { disease }\end{array}$} & M & 1 & 2 & 3 & 6 \\
\hline & $\mathrm{F}$ & 0 & 0 & 2 & 2 \\
\hline \multirow[t]{2}{*}{ Other cardiac death } & M & 0 & 0 & 0 & 0 \\
\hline & $\mathrm{F}$ & 0 & 0 & 2 & 2 \\
\hline \multirow[t]{2}{*}{ Total violent death } & M & $6(35)$ & $11(37)$ & $9(32)$ & $26(35)$ \\
\hline & $\mathrm{F}$ & 0 & $2(20)$ & $1(11)$ & $3(11)$ \\
\hline \multirow[t]{2}{*}{ Suicide } & M & 2 & 5 & 4 & 11 \\
\hline & $\mathrm{F}$ & 0 & 1 & 1 & 2 \\
\hline \multirow[t]{2}{*}{ Accidents } & M & 4 & 6 & 2 & 12 \\
\hline & $\mathrm{F}$ & 0 & 1 & 0 & 1 \\
\hline \multirow[t]{2}{*}{ Intoxication } & M & 0 & 0 & 3 & 3 \\
\hline & $\mathrm{F}$ & 0 & 0 & 0 & 0 \\
\hline \multirow{2}{*}{$\begin{array}{l}\text { Total acute metabolic } \\
\text { complications }\end{array}$} & M & $6(35)$ & $7(23)$ & $2(7)$ & $15(20)$ \\
\hline & $\mathrm{F}$ & $4(45)$ & $4(40)$ & 0 & $8(29)$ \\
\hline \multirow[t]{2}{*}{ Hypoglycaemia } & M & 0 & 4 & 2 & 6 \\
\hline & $\mathrm{F}$ & 1 & 3 & 0 & 4 \\
\hline \multirow[t]{2}{*}{ Diabetic ketoacidosis } & M & 6 & 3 & 0 & 9 \\
\hline & $\mathrm{F}$ & 3 & 1 & 0 & 4 \\
\hline \multirow[t]{2}{*}{ Renal disease } & M & 0 & 1 & $4(14)$ & $5(7)$ \\
\hline & $\mathrm{F}$ & $1(11)$ & 0 & $2(22)$ & $3(11)$ \\
\hline \multirow{2}{*}{$\begin{array}{l}\text { Death caused by } \\
\text { infection }\end{array}$} & $\mathrm{M}$ & $1(6)$ & $1(3)$ & 0 & $2(3)$ \\
\hline & $\mathrm{F}$ & $2(22)$ & $1(10)$ & 0 & $3(11)$ \\
\hline \multirow{2}{*}{$\begin{array}{l}\text { Sudden death/ } \\
\text { unexpected death }\end{array}$} & M & $1(6)$ & $5(17)$ & $7(25)$ & $13(17)$ \\
\hline & $\mathrm{F}$ & $1(11)$ & $2(20)$ & $1(11)$ & $4(14)$ \\
\hline \multirow[t]{2}{*}{ Other causes $^{\mathrm{a}}$} & M & $2(12)$ & $2(7)$ & 0 & $4(5)$ \\
\hline & $\mathrm{F}$ & $1(11)$ & $1(10)$ & 0 & $2(7)$ \\
\hline \multirow[t]{2}{*}{ All causes } & $\mathrm{M}$ & 17 (100) & $30(100)$ & $28(100)$ & 75 (100) \\
\hline & $\mathrm{F}$ & $9(100)$ & $10(100)$ & $9(100)$ & $28(100)$ \\
\hline
\end{tabular}

${ }^{a}$ Male 9 months, unknown cause/encephalopathy; male 13 years, asthma bronchial; male 24 years, cancer coli; male 25 years, cancer larynx; female 19 years, pulmonary embolism (amnion fluid); female 29 years, anorexia nervosa 
Table 4 Mortality rates and standardised mortality ratios for causes of death in cohort members by sex
Age at death: $0-40$ years ${ }^{a}$ Rate per 100,000 person-years CVD Cardiovascular disease, SMR Standardised mortality ratio

\begin{tabular}{|c|c|c|c|c|c|}
\hline Cause of death & Sex & No. of deaths & Rate in cohort ${ }^{\mathrm{a}}$ & Rate in general population ${ }^{a}$ & SMR $(95 \%$ CI) \\
\hline \multirow{2}{*}{$\begin{array}{l}\text { Ischaemic heart } \\
\text { disease }\end{array}$} & M & 6 & 26.3 & 1.3 & $20.2(7.3-39.8)$ \\
\hline & $\mathrm{F}$ & 2 & 10.3 & 0.5 & $20.6(1.8-54.2)$ \\
\hline \multirow{2}{*}{$\begin{array}{l}\text { Cerebrovascular } \\
\text { death }\end{array}$} & M & 4 & 17.6 & 0.7 & $25.1(6.9-59.0)$ \\
\hline & $\mathrm{F}$ & 0 & 0 & 0.4 & \\
\hline \multirow[b]{2}{*}{$\begin{array}{l}\text { CVD (including } \\
\text { ischaemic heart } \\
\text { disease and } \\
\text { cerebrovascular } \\
\text { disease) }\end{array}$} & M & 10 & 43.9 & 4.0 & $11.0(5.2-18.8)$ \\
\hline & $\mathrm{F}$ & 4 & 20.6 & 2.0 & $10.3(2.7-22.7)$ \\
\hline \multirow[t]{2}{*}{ Suicide } & M & 5 & 21.9 & 16.1 & $1.4(0.3-2.3)$ \\
\hline & $\mathrm{F}$ & 1 & 5.2 & 3.8 & $1.4(0.0-4.5)$ \\
\hline \multirow{2}{*}{$\begin{array}{l}\text { Violent death } \\
\text { (excluding } \\
\text { suicide) }\end{array}$} & M & 21 & 92.2 & 27.8 & $3.3(2.0-4.9)$ \\
\hline & $\mathrm{F}$ & 3 & 15.5 & 9.3 & $1.7(0.3-4.1)$ \\
\hline \multirow[t]{2}{*}{ Renal disease } & M & 5 & 22.0 & 0.1 & $220(82-488)$ \\
\hline & $\mathrm{F}$ & 3 & 15.5 & 0.1 & $155(29-384)$ \\
\hline
\end{tabular}

Diabetes was mentioned on the death certificate in $67 \%$ of the 103 cases. A higher proportion of women than men had diabetes mentioned on the death certificate ( $79 \%$ vs $63 \%$ ). Diabetes was mentioned on the death certificate for $28 \%$ of the violent deaths, $87 \%$ of the deaths with acute diabetic complications and $82 \%$ of the cardiovascular deaths.

Causes of death based on death certificates and the ICD codes from the cause of death registry

In the total cohort, diabetes was most commonly listed as the cause of death, accounting for $41 \%$ of the cases; violent death was the second most common cause (29\%). The underlying causes of death exhibited by this cohort are shown in the Electronic Supplementary Material (ESM) Table 1.

Causes of death assessed by the clinical review committee

The clinical review committee examined all available information from the 103 deaths and reclassified the cause of death in 53 subjects. The whole group with diabetes as the cause of death $(n=42)$ was reclassified: 14 to sudden death, 13 to DKA, ten to hypoglycaemia, four to infection and one to violent death. One death initially classified as intoxication was reclassified to hypoglycaemia, three cases from epilepsy to sudden death, and seven cases from accident to suicide. The most frequent causes of death in the total cohort after reclassification were violent deaths, acute metabolic complications and cardiovascular disease (CVD) (Table 3). CAD was verified by autopsy $(n=4)$ or by clinical findings in an intensive care unit $(n=3)$. In one case the diagnosis was made after assessing detailed symptoms before death noted by a physician. The two most frequent causes of death below 20 years of age were acute metabolic complications (38\%) and violent deaths $(23 \%)$. The youngest person who died of ischaemic heart disease (IHD) was a 16-year-old male. Diabetes duration at death was 4.6 years and he had no other known disorders. Myocardial infarction was confirmed by autopsy. Between the ages of 20 and 30 years, acute metabolic complications $(28 \%)$ and violent deaths $(33 \%)$ were still the two most frequent causes of death. From the age of 30 years onwards CVD (30\%) was the most common cause of death in the total cohort. Sudden death accounted for $17 \%$ of all the deaths in the total cohort.

When addressing cause-specific deaths by diabetes duration in our cohort (ESM Table 2), the most common cause of death during the first 10 years of diabetes was acute metabolic complications (42\%). Violent deaths (29\%) were responsible for the major proportion of death from 10 years of diabetes duration onwards. Acute metabolic complications $(22 \%)$ were the second most common cause of death after $10-19$ years and CVD (26\%) after 20 years of diabetes duration.

Standardised mortality ratios for causes of death

For IHD the mortality rates for the patients with type 1 diabetes were 20 -fold higher than in the general population; rates were similar in men and women (Table 4). Men with type 1 diabetes had a two-fold increased risk of dying a violent death compared with the general population, but this was not the case for women with type 1 diabetes. Although a small proportion of deaths was attributed to renal disease, SMRs were very high for renal deaths.

\section{Discussion}

We report a considerably increased risk of total and cardiovascular death in a nationwide cohort of patients with childhood-onset type 1 diabetes in a country with 
good access to a public healthcare system that is inexpensive for the patients.

Our study evaluated absolute and relative mortality rates for childhood-onset type 1 diabetes, the effects of sex and age at diagnosis, and the cause of death. The study cohort was nationwide and the study itself had one of the longest follow-up periods of a cohort of patients with childhoodonset type 1 diabetes (30 years). The large number of people studied, the almost complete follow-up and the linkage to the Cause of Death registry enable us to draw firm conclusions. Since the cause of death in patients with type 1 diabetes is frequently misclassified $[25,26]$, we reclassified causes of death after critically assessing all available information. We did not reclassify deaths in the background population and therefore we used ICD codes for the estimation of SMR, to avoid bias caused by reclassification of only patients with type 1 diabetes. An inherent problem with mortality studies is that in some cases the classification of causes of death is notoriously difficult, even with access to autopsy reports and other information. Moreover, the differences between background mortality rates in general populations adds a further confounding factor in attempts to compare independent cohort studies [11, 12,27]. We believe that few children in Norway die of DKA before being diagnosed with type 1 diabetes, although we cannot exclude this possibility completely.

Most of the published studies on mortality in patients with type 1 diabetes are clinic-based, from hospitals that specialise in diabetes care, and are not necessarily representative of the general type 1 diabetes population. Only a few studies have been population-based $[7,14,15,28$, 29]. In accordance with recent reports from other countries, individuals with childhood-onset type 1 diabetes demonstrate excess mortality compared with the general population at all ages $[13,14,30,31]$, and the SMR in the present study was of a magnitude similar to those found in Finland, Estonia and Lithuania [8, 14]. Mortality from childhood-onset type 1 diabetes differs markedly from country to country. In recent studies [7-9] from different countries the SMR is as follows: Finland, 3.7; USA (Allegheny County, PA), 5.2; Israel, 3.0; Japan, 12.9. It seems that data from European countries are more favourable compared with those from the USA and Japan. On the other hand, data from Israel show a lower SMR compared with Finland and Norway. Differences in methods, background populations and the populations studied make comparisons difficult. In the countries where mortality in persons with diabetes is reported to be lower than in the USA and Japan, free medical care is provided for type 1 diabetes. The reason for a higher mortality rate in the USA may relate to the costly healthcare system for diabetes [2]; the high financial burden may keep patients from frequent contact with physicians. In Japan, the healthcare system for type 1 diabetes was poorly developed before the 1980s [32], at least partly because Japan has an extremely low incidence of type 1 diabetes [33].

The DERI Mortality Study Group [30] and other studies $[5,31]$ have reported that the SMRs were markedly higher for females compared with males in Japan, Israel, USA (Allegheny County, PA), UK and Sweden, but not in Finland [30]. In our cohort we found that males had a twofold higher absolute mortality rate than females, but the SMR was similar for men and women, reflecting the higher background mortality in men.

The mortality of patients with diabetes diagnosed between 1925 and 1955 from Oslo, Norway, and followed until 1961 was published by Westlund [34]. Although the methods employed are not directly comparable with those used in the present study, it is the only previous study that presents mortality data for diabetic subjects in Norway diagnosed before 1958. The mortality rate for young diabetic subjects ( $<30$ years old at follow-up) was approximately 10/1,000 person-years. In the present study we found this rate to be $2.2 / 1,000$ person-years. Comparing these rates, there appears to have been a major reduction in the mortality associated with type 1 diabetes in Norway.

In this study we could not prove any significant temporal trend in mortality. Only a few studies have examined temporal trends in mortality associated with childhoodonset type 1 diabetes. A study from the USA (Allegheny County, PA) based on type 1 diabetic patients diagnosed before 18 years between 1965 and 1979 reported a significant improvement in the survival rate between the cohort diagnosed during 1965-1969 and that diagnosed during 1975-1979 [9]. Comparison between Japan and Finland of the mortality rate of childhood-onset type 1 diabetes cases diagnosed between 1965 and 1979 was performed as of 1995 [8]. Finland showed no improving tendency when the mortality of the cases diagnosed between 1975 and 1979 was compared with that for 1965-1969. In Japan, a dramatic improvement was observed between 1969 and 1979. However, Podar et al. [14] report a further decline in the mortality of childhood-onset type 1 diabetes in Finland, diagnosed during 1980-1994.

It has been claimed that the younger the patient is at the onset of type 1 diabetes, the shorter he lives [27]. This is contrary to the finding of the present study. The reason might be that in the past acute metabolic complications were responsible for the majority of deaths in the youngest age group. It seems that this cause of death, though still high, has decreased. A reason might be greater awareness among medical staff and parents, leading to earlier diagnosis and adequate management of acute complications. The present study shows that acute metabolic complications were the largest single cause of death under the age of 30 years. This is in keeping with a recent study from the UK [13]. In terms of preventable deaths, DKA among already diagnosed cases certainly belongs to this group. In this cohort, 15 patients died of DKA; 13 had had diabetes for several years and two died at diabetes onset.

The mortality rates from IHD in females with type 1 diabetes were not only greater than for women without diabetes, but were also considerably higher than for men without diabetes. In the general population mortality from IHD was much higher in men than in women. In our diabetes cohort the mortality from IHD was also higher in 
men than women, in contrast to data from the UK reporting no difference between the sexes under the age of 40 years [35]. Several previous studies [35-37] have found diabetes to be a greater risk factor for morbidity and mortality from CVD in women than in men. The mortality rates from IHD in the general population are similar in the UK [35] and Norway. We found the SMR for IHD in women to be lower than that reported from the UK [35], and notably higher in men.

The cause of unexpected and sudden death is ill-defined. In the background population these deaths are usually classified as CAD. For diabetic patients there is reason to believe that both cardiac autonomic dysfunction and concomitant hypoglycaemia are involved, and that malignant cardiac dysrhythmias might be a common final pathway [38]. It has been recognised that patients with cardiac autonomic neuropathy secondary to diabetes sometimes die a sudden and unexpected death without an obvious cause apparent at autopsy [39]. Sudden death might also be the result of occult coronary disease. This means that death caused by acute diabetes complications and CVD may be underestimated to some extent.

When assessing the causes of death based on death certificates and the ICD codes from the Cause of Death registry, no deaths were registered as unexpected or sudden deaths. However, we had a large group of deaths $(n=42)$ registered as diabetes mellitus. The clinical review committee reclassified 14 (twelve males, two females) of these deaths to unexpected/sudden death. None of them died in hospital; 13 died at home. Six of the deceased had an autopsy (five males and one female). None of the autopsy reports were informative. It is well documented how difficult it is to diagnose acute metabolic complications or fatal arrhythmia at autopsy [40]. Four of these deaths met the criteria for dead-in-bed syndrome [41]: three males (12, 21 and 24 years) and one female (19 years). Autopsy was performed in all cases. These cases amount to $3.9 \%$ of all deaths, which is less than observed by others [31, 41]. Fatal cardiac dysrhythmias are considered the cause of dead-inbed syndrome, which might be provoked by an episode of hypoglycaemia [42].

We found a high death rate from violent deaths, especially in males, in whom it was the greatest single cause of death under 30 years of age. In the age group 3044 years it was exceeded only by CVD as a cause of death. Although the death rate from violent deaths in the general population was high in young males, it did constitute a twofold increased risk of death in our cohort. The mortality rates from violent deaths in women were much lower than in men. By assessing each of the 13 deaths due to accidents, we tried to explore to what extent the accident might have been related to hypoglycaemia. This is difficult to assess, but some of the accidents were clearly not diabetes-related, such as car accidents in which the patient was not the driver $(n=3)$, obstruction of the respiratory tract by food $(n=1)$ and avalanche $(n=1)$. There were six accidents that might have been related to hypoglycaemia: one fall from a balcony, four car/motorcycle accidents in which the patient was the driver, and one case of hypothermia during mountain hiking. Two of the accidents were difficult to categorise: one drowning and a car accident in which the patient was hit by a car. Seven of the 13 deceased had an autopsy; none of them screened positive for alcohol.

The clinical review committee reclassified seven causes of death from accidents to suicides. There is reason to believe that this under-reporting of suicide is similar both for the patient cohort and for the background population. The mortality from suicide was not significantly greater in patients with diabetes compared with the general population. However, the clinical review committee indicated that suicide had been under-reported and found $13 \%$ of the total deaths to be suicides. This high number of suicides may indicate increased psychiatric vulnerability and burden associated with childhood-onset type 1 diabetes.

Renal disease has previously been identified as a major cause of death in patients with type 1 diabetes [28]. In our study, end-stage renal failure was responsible for $8 \%$ of all deaths. The SMR was high for this cause, from which few deaths occur in patients without diabetes, especially at young ages. At all ages the number of deaths certified to CVD exceeded those certified to renal disease.

In conclusion, childhood-onset type 1 diabetes still carries an increased mortality risk when compared with the nondiabetic population in Norway, particularly for IHD. Attention should be directed to the prevention of acute metabolic complications, the identification of psychiatric vulnerability, strategies to prevent coronary atherosclerosis and the early detection and treatment of cardiovascular risk factors.

Acknowledgements This study was supported by grants from the Norwegian Diabetes Association and Diabetes Research Centre, Aker and Ullevål University Hospital.

\section{References}

1. Marks HH (1965) Longevity and mortality of diabetics. Am J Public Health 55:416-423

2. DERI Mortality Study Group (1995) International analysis of insulin-dependent diabetes mellitus mortality: a preventable mortality perspective. Am J Epidemiol 142:612-618

3. WHO Multinational Project for Childhood Diabetes (1990) WHO Diamond Project Group. Diabetes Care 13:1062-1068

4. Fuller JH, Elford J, Goldblatt P, Adelstein AM (1983) Diabetes mortality: new light on an underestimated public health problem. Diabetologia 24:336-341

5. Laing SP, Swerdlow AJ, Slater SD et al (1999) The British Diabetic Association Cohort Study, I: all-cause mortality in patients with insulin-treated diabetes mellitus. Diabet Med 16: 459-465

6. Andresen EM, Lee JAH, Pecoraro RE, Koepsell TD, Hallstrom AP, Siscovick DS (1993) Underreporting of diabetes on death certificates, King County, Washington. Am J Public Health 83:1021-1024

7. Laron-Kenet T, Shamis I, Weitzman S, Rosen S, Laron ZVI (2001) Mortality of patients with childhood onset (0-17 years) type 1 diabetes in Israel: a population-based study. Diabetologia 44(Suppl 3):B81-B86

8. Asao K, Sarti C, Forsen T et al (2003) Long-term mortality in nationwide cohorts of childhood-onset type 1 diabetes in Japan and Finland. Diabetes Care 26:2037-2042 
9. Nishimura R, LaPorte RE, Dorman JS, Tajima N, Becker D, Orchard TJ (2001) Mortality trends in type 1 diabetes. Diabetes Care 24:823-827

10. Lestradet H, Papoz L, Hellouin de Menibus CL et al (1981) Long-term study of mortality and vascular complications in juvenile-onset (type I) diabetes. Diabetes 30:175-179

11. DERI Mortality Study Group (1991) Major cross-country differences in risk of dying for people with IDDM. Diabetes Care 14:49-54

12. Diabetes Epidemiology Research International (DERI) Mortality Study Group (1991) International evaluation of cause specific mortality and IDDM. Diabetes Care 14:55-60

13. Laing SP, Swerdlow AJ, Slater SD et al (1999) The British Diabetic Association Cohort Study, II: cause-specific mortality in patients with insulin-treated diabetes mellitus. Diabet Med $16: 466-471$

14. Podar T, Solntsev A, Reunanen A et al (2000) Mortality in patients with childhood-onset type 1 diabetes in Finland, Estonia, and Lithuania. Diabetes Care 23:290-294

15. Sartor G, Nystrom L, Dahlquist G (1991) The Swedish Childhood Diabetes Study: a seven-fold decrease in shortterm mortality? Diabet Med 8:18-21

16. Joner G, Sovik O (1989) Increasing incidence of diabetes mellitus in Norwegian children 0-14 years of age 1973-1982. Diabetologia 32:79-83

17. International Classification of Diseases, Eight Revision (ICD-8) (1985) Central Bureau of Statistics of Norway, Oslo

18. International Classification of Diseases, Ninth Revision (ICD9) (1986) Central Bureau of Statistics of Norway, Oslo

19. International Classification of Diseases, Tenth Revision (ICD10) (2000) Norwegian Board of Health, Oslo

20. Swerdlow AJ, Jones ME (1996) Mortality during 25 years of follow-up of a cohort with diabetes. Int J Epidemiol 25:12501261

21. Kilpatric SJ (1962) Occupational mortality indices. Popul Stud $16: 175$

22. Hill AB (1971) Principles of medical statistics, 9th edn. Oxford University Press, New York

23. Breslow NE, Day NE (1987) Statistical methods in cancer research, vol. 2. The design and analysis of cohort studies. IARC, Lyon

24. Population Statistics (2002) Central Bureau of Statistics of Norway, Oslo

25. Start RD, Bury JP, Strachan AG, Cross SS, Underwood JCE (1997) Evaluating the reliability of causes of death in published clinical research. BMJ 314:271
26. Muhlhauser I, Sawicki PT, Blank M, Overmann H, Richter B, Berger M (2002) Reliability of causes of death in persons with type 1 diabetes. Diabetologia 45:1490-1497

27. Panzram G (1984) Epidemiologic data on excess mortality and life expectancy in insulin-dependent diabetes mellitus - critical review. Exp Clin Endocrinol 83:93-100

28. Dorman JS, LaPorte RE, Kuller LH et al (1984) The Pittsburgh insulin-dependent diabetes mellitus (IDDM) morbidity and mortality study: mortality results. Diabetes 33:271-276

29. Joner G, Patrick S (1991) The mortality of children with type 1 (insulin-dependent) diabetes mellitus in Norway, 1973-1988. Diabetologia 34:29-32

30. DERI Mortality Study Group (1991) Sex differences in the mortality associated with insulin-dependent diabetes mellitus in four countries. Am J Epidemiol 133:577-584

31. Sartor G, Dahlquist G (1995) Short-term mortality in childhood onset insulin-dependent diabetes mellitus: a high frequency of unexpected deaths in bed. Diabet Med 12:607-611

32. The Diabetes Epidemiology Research International (DERI) Study Group (1996) A major improvement in the prognosis of individuals with IDDM in the past 30 years in Japan. Diabetes Care 19:758-760

33. Karvonen M, Viik-Kajander M, Moltchanova E, Libman I, LaPorte R, Tuomilehto J (2000) Incidence of childhood type 1 diabetes worldwide. Diabetes Care 23:1516-1526

34. Westlund K (1969) Mortality of diabetics. Norwegian University Press, Oslo

35. Laing SP, Swerdlow AJ, Slater SD et al (2003) Mortality from heart disease in a cohort of 23,000 patients with insulin-treated diabetes. Diabetologia 46:760-765

36. Lerner DJ, Kannel WB (1986) Patterns of coronary heart disease morbidity and mortality in the sexes: a 26-year followup of the Framingham population. Am Heart J 111:383-390

37. Colhoun HM, Rubens MB, Underwood SR, Fuller JH (2000) The effect of type 1 diabetes mellitus on the gender difference in coronary artery calcification. J Am Coll Cardiol 36:2160-2167

38. McNally PG, Lawrence IG, Panerai RB, Weston PJ, Thurston $H$ (1995) Sudden death in type 1 diabetes. Diabetes Obes Metab 1:151-158

39. Page McB, Watkins PJ (1978) Cardio-respiratory arrest and diabetic autonomic neuropathy. Lancet 1(8054):14-16

40. Tattersall RB, Gill GV (1991) Unexplained deaths of type 1 diabetic patients. Diabet Med 8:49-58

41. Thordarson H, Søvik O (1995) Dead in bed syndrome in young diabetic patients in Norway. Diabet Med 12:782-787

42. Harris ND, Heller SR (1999) Sudden death in young type 1 diabetic patients. Diabet Med 16:623-625 